\title{
Evaluation of mobile applications related to nutrition
}

\author{
Vitória Negri Braz ${ }^{1}$ and Maria Helena Baena de Moraes Lopes ${ }^{2, *}$ \\ ${ }^{1}$ Faculty of Nutrition, Pontifícia Universidade Católica de Campinas (PUCCAMP), Campinas, SP, Brazil: ${ }^{2}$ Faculty of \\ Nursing, University of Campinas (UNICAMP), Tessália Vieira de Camargo 126, Cidade Universitária, Campinas, CEP \\ 13083-887, SP, Brazil
}

Submitted 4 October 2017: Final revision received 14 March 2018: Accepted 26 March 2018: First published online 8 May 2018

\begin{abstract}
Objective: To verify the reliability of information, the sources of information used and the user opinions of the free mobile applications (apps) with nutritional information available in Brazil.

Design: Descriptive, cross-sectional study.

Setting: We evaluated the content about nutrition of free apps available on the App Store of iPhone 5S with software iOS 8.4.1 and on the Play Store of the Android platform, version 2.3.6. For this, we compared the nutrition information provided by the app with (i) the Brazilian Food Composition Table (TACO), of 2011; (ii) food composition table: support for nutritional decision, of 2002; and (iii) the National Study of Family Expenditure: food composition tables, of 1999. The evaluation included the description and quantity of macro- and micronutrients in foods. In addition, we evaluated the trustworthiness of information about food energy values and analysed the comments and ratings made by users.

Subjects: Mobile apps related to nutrition.

Results: We assessed sixteen apps for mobile devices. Considering the foods selected (a basic Brazilian food basket for the month of August 2015), the apps presented partially adequate or inadequate information about food composition (macro- and micronutrients). The adequacy of the food energy values ranged from 0 to $57 \cdot 1 \%$. Despite this, the apps received positive ratings by users.

Conclusions: The mobile apps about nutrition currently available and evaluated in the present study in Brazil are not useful for nutritional guidance because most of them are not based on reliable sources of information.
\end{abstract}

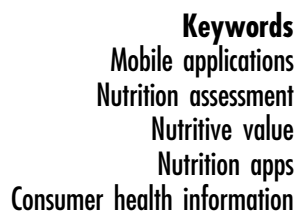

Information and communication technologies are defined as those that assist the collection, processing, storage and exchange of information by electronic transmission. In health, these technologies enable the promotion of a healthy lifestyle, examples being electronic records, telehealth services, health information networks, tools that health professionals use and that support clinical decision making, and Internet-based technologies and services ${ }^{(1)}$.

The use of mobile devices is increasingly common and advantageous these days, because this tool provides access to information at any time and by any individual. Regarding applications (apps) about nutrition, they are designed to bring the individual to a lifestyle change, since they intend to make users think about food choices by the demonstration of food nutritional content ${ }^{(2)}$. Besides that, the main goals of the nutrition apps are: 'providing feedback, goal-setting for healthy eating, healthy cooking, self-monitoring of energy and nutrient intake, weight tracking, planning social support and change' and the choice of places to eat ${ }^{(3)}$.

The variety of nutrition-related apps is increasing nowadays; however, some of them do not offer correct nutritional information ${ }^{(4)}$. On the other hand, one of the advantages of using apps in nutritional practice is that they can be used by both professionals and customers, strengthening their relationship ${ }^{(5)}$. In addition, free apps can be accessed by an unlimited group of users. Also, it is important to emphasize that apps 'must be critically examined' in relation to the 'missing information about data sources and providers ${ }^{,(6)}$.

Some nutrition-related health apps intend to help people change their behaviour by the practice of physical activity and usual intake reminder, so that the more accurate the tool is, the greater the effectiveness of the predicted result ${ }^{(7)}$.

For nutritionists and other health professionals to recommend its use as a helpful resource for access to information about foods and their nutritional and energy values, the app must be evaluated according to welldefined criteria such as its purpose and reliability of because the use of mobile apps is recent. Therefore, our study aimed to verify the reliability of information, the information. However, research on this topic is still scarce 
sources of information used and user opinions of free mobile apps with nutritional information available in Brazil.

\section{Methods}

This was a descriptive, cross-sectional study. We evaluated apps on nutrition found in the App Store of iPhone $5 \mathrm{~S}$ with software iOS 8.4.1 and on the Play Store for the Android platform, version 2.3.6, from August to November 2015.

Inclusion criteria were: free apps, addressing the composition and energy value of foods, available in Brazil, produced or not in the country, in English or Portuguese. We excluded apps that did not have the assessment of users.

Apps were evaluated regarding the following variables.

1. Goal of the application: the purpose informed by the app, for example 'monitoring diet and exercise'.

2. Reliability of information on food composition: we used the most current available version of the Brazilian Food Composition Table (TACO 2011) ${ }^{(8)}$. The food composition information was evaluated in relation to the description of macro- and micronutrients, as well as their quantities. We considered the app 'adequate' when it presented all macro- and micronutrients described in TACO, as well as the correct amounts; 'partially adequate' when it described, in addition to those expected, other macro- and micronutrients not mentioned in TACO, or when all macro- and micronutrients listed in TACO were not described, but the values were correct; or 'inadequate' if did not describe the macroand micronutrients of TACO and/or when not indicating the correct amounts of macro- and micronutrients.

3. Reliability of information about food energy value: we evaluated this on the basis of the average values of food energy calculated from those indicated in three tables, namely: (i) the Brazilian Food Composition Table (TACO 2011) ${ }^{(8)}$; (ii) the food composition table: support for nutritional decision, of $2002^{(9)}$; and (iii) the National Study of Family Expenditure: food composition tables, of $1999^{(10)}$. The applications were evaluated as reliable or not, accepting a variation of up to one standard deviation in the reported energy values. After calculation and analysis of the energy value of each food, we calculated the percentage of adequacy as follows: (total number of foods with correct energy value/total number of foods evaluated) $\times 100$.

4. Calculation of BMI: according to the formula recommended by the $\mathrm{WHO}^{(11)}$. To verify whether the calculation performed by the app was correct, we adopted as standard the weight of $70 \mathrm{~kg}$ and height of $1.70 \mathrm{~m}$. The apps were classified as having this feature or not, and we evaluated whether the calculation was correct or not.

5. Consulted sources: we verified whether the app pointed to the sources of information about food composition and energy value, namely food composition tables, food labels and others.

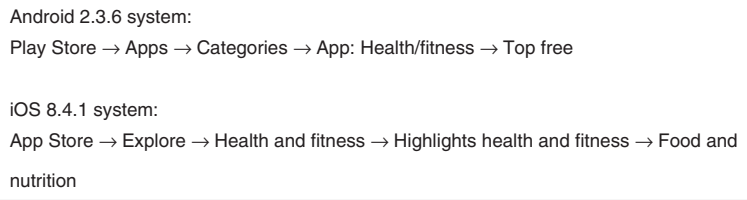

Fig. 1 Steps for accessing applications (apps) according to Android 2.3.6 or iOS 8.4.1 system

6. User opinion: ratings and comments recorded by the users of the app. Users did not complete forms developed by the authors; the app defined how that evaluation should be made by the user. In the apps that received over 100 ratings or comments, only the total number of ratings was registered. We also evaluated the average number of stars that the app received from users, when existing. When we recorded comments, they were grouped according to content and categorized as positive or negative.

To evaluate the trustworthiness of the information about food composition and energy, we selected for analysis the foods that made up the basic Brazilian food basket for the month of August 2015 ${ }^{(12)}$, namely refined sugar, cooked white rice, lady finger banana, boiled potatoes, grilled steak (sirloin steak), cooked carioca beans, whole milk, unsalted butter, canola oil, French rolls and tomatoes. In addition, we included other foods commonly consumed by the Brazilian population: loose leaf lettuce, cooked pasta and cola-based soda.

As access to apps is different in each system, we used the steps described in Fig. 1.

\section{Results}

We evaluated sixteen apps for mobile devices from App Store, software iOS 8.4.1 and from Play Store, Android platform, version 2.3.6. The goals of the apps, calculation of BMI, sources consulted for the nutritional information, comments and user ratings are described in Table 1.

The mobile apps evaluated aimed mainly at monitoring the diet and physical exercise performed by users. Besides this, other goals often mentioned were following daily meals, controlling energy (calories) ingested and promoting healthy habits.

Based on Table 1, we were able to observe that only $37.5 \%$ of apps calculated user BMI and, among them, one reported the incorrect value.

Regarding the sources used, only two apps (App1 and App14) mentioned food composition tables and other documents, and four (App2, App3, App4 and App11) used the food label as a reference. Therefore, most (62.5\%) did not mention the source of food composition information.

According to Table 1, only two apps were not evaluated by users, and three apps received 5 stars. Most of them ( $n$ 10; $62.5 \%$ ) received 4 or 4.5 stars, indicating that the rating was, in general, positive. 


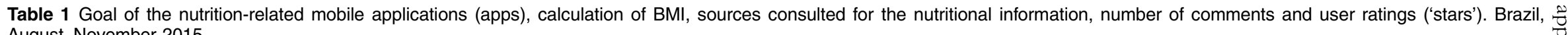
August-November 2015

\begin{tabular}{|c|c|c|c|c|c|}
\hline App code & Goal of app & Calculation of BMI & Sources consulted & $\begin{array}{l}\text { No. of } \\
\text { comments }\end{array}$ & $\begin{array}{l}\text { User rating } \\
\text { (no. of stars) }\end{array}$ \\
\hline App1 & Monitoring diet and exercise & Absent & $\begin{array}{l}\operatorname{TACO}^{(8)} \\
\text { Philippi }^{(9)} \\
\text { Food label }\end{array}$ & 23 & 4.5 \\
\hline App2 & $\begin{array}{l}\text { Monitoring diet and exercise } \\
\text { Helping in the choice of food } \\
\text { Improving eating habits }\end{array}$ & Present and correct & Labels & 75 & 4.5 \\
\hline App3 & $\begin{array}{l}\text { Finding nutritional information of food ingested } \\
\text { Following meals, exercise and weight evolution }\end{array}$ & Absent & Labels & 20 & $4 \cdot 5$ \\
\hline App4 & Enduring weight loss & Absent & $\begin{array}{l}\text { Labels } \\
\text { Some foods presented macronutrient composition } \\
\text { equal to that of } \operatorname{TACO}^{(8)} \text {, but without reference to it }\end{array}$ & 6695 & 4 \\
\hline App5 & $\begin{array}{l}\text { Indicating the foods that users must eat to reach their health goals } \\
\text { based on their medical profile, goals and culinary preferences }\end{array}$ & Absent & Not mentioned & 55 & 4.5 \\
\hline App6 & $\begin{array}{l}\text { Being an energy (calorie) counter that rewards users when they eat a } \\
\text { healthy meal and punishes them when they do the opposite } \\
\text { Promoting healthy habits }\end{array}$ & Absent & Not mentioned & 8 & 4.5 \\
\hline App7 & $\begin{array}{l}\text { Improving eating habits, helping weight management and health } \\
\text { maintenance }\end{array}$ & Absent & Not mentioned & None & None \\
\hline App8 & $\begin{array}{l}\text { Being an energy (calorie) and macronutrient counter for individuals } \\
\text { who are controlling the intake of macronutrients to reach the goals } \\
\text { regarded as 'fitness' }\end{array}$ & Absent & Not mentioned & 1 & 5 \\
\hline App9 & Helping users to improve eating habits and lose weight & Absent & Not mentioned & 4 & 4.5 \\
\hline App10 & $\begin{array}{l}\text { Helping in the control of food and drink intake by real-time food check- } \\
\text { in, thus the app indicates how is the users' course of the day and } \\
\text { where they can improve }\end{array}$ & Absent & Not mentioned & None & None \\
\hline App11 & Monitoring the daily energy (calories) ingested and staying in shape & Present and incorrect & Labels & 5 & 4 \\
\hline App12 & $\begin{array}{l}\text { Conquering goals, whether to lose weight, maintain weight or have a } \\
\text { healthier life }\end{array}$ & Present and correct & Not mentioned & 32017 & 5 \\
\hline App13 & $\begin{array}{l}\text { Controlling weight in a healthy way, helping users to acquire control } \\
\text { over their choices }\end{array}$ & Present and correct & Not mentioned & 4173 & 5 \\
\hline App14 & $\begin{array}{l}\text { Providing useful information in the pursuit of a healthy and balanced } \\
\text { nutrition }\end{array}$ & Present and correct & $\begin{array}{l}\text { Food composition: } \mathrm{TACO}^{(8)} \\
\text { Three and seven skinfolds: Guedes }{ }^{(27)} \\
\text { Daily energy: Harris and Benedict }{ }^{(28)} \\
\text { Expenditure of energy in activities: Ainsworth } \\
\text { et al. }{ }^{(29)} \\
\text { Ten steps to a healthy diet: Brazilian Ministry of } \\
\text { Health }{ }^{(30)}\end{array}$ & 2517 & 4 \\
\hline App15 & Controlling weight and energy (calorie) intake & Present and correct & Not mentioned & 1492 & 4 \\
\hline App16 & $\begin{array}{l}\text { Helping in loss of energy (calories) and weight with the complete } \\
\text { table of energy (calories) }\end{array}$ & Absent & Not mentioned & 864 & 3.7 \\
\hline
\end{tabular}

TACO, Brazilian Food Composition Table.

*Star value reported by the app. 
Some examples of positive reviews were: 'practical and easy-to-use app'; 'it helps in the decision of choosing food'; 'it has graphs to accompany the evolution of weight'; 'interaction with social network'; 'it is possible to get a dietary re-education'; 'great database'; 'it helps in weight control'; 'great design'; 'control of macronutrients'; 'this app has motivated me to pay attention to dietary habits'; and 'while using the app, motivational messages appear'.

On the other hand, some examples of negative opinions were also found: 'some foods are in English'; 'the app is in trouble updating'; 'hard to use'; 'one should be able to put the meal times'; and 'the app is not in Portuguese'.

According to Table 2, no app was evaluated as adequate. Six apps presented between 21.43 and $85.71 \%$ of

Table 2 Reliability of the nutrition-related mobile applications (apps) analysed, according to the evaluation of food composition and energy value*. Brazil, August-November 2015

\begin{tabular}{|c|c|c|}
\hline $\begin{array}{l}\text { App } \\
\text { code }\end{array}$ & $\begin{array}{l}\text { Evaluation of food } \\
\text { composition }(\%)\end{array}$ & $\begin{array}{l}\text { Adequacy of food } \\
\text { energy value }(\%)\end{array}$ \\
\hline App1 & $\begin{array}{l}\text { Partially adequate }=21.43 \% \\
\text { Inadequate }=64.28 \% \\
\text { Foods not listed on TACO }=14.28 \%\end{array}$ & 21.43 \\
\hline App2 & $\begin{array}{l}\text { Partially adequate }=21.43 \% \\
\text { Inadequate }=64.28 \% \\
\text { Foods not listed on TACO }=14.28 \%\end{array}$ & 28.57 \\
\hline App3 & $\begin{array}{l}\text { Partially adequate }=21.43 \% \\
\text { Inadequate }=64.28 \% \\
\text { Foods not listed on TACO }=14.28 \%\end{array}$ & $57 \cdot 14$ \\
\hline App4 & $\begin{array}{l}\text { Partially adequate }=57.14 \% \\
\text { Inadequate }=28.57 \% \\
\text { Foods not listed on TACO }=14.28 \%\end{array}$ & 37.71 \\
\hline App5 & $\begin{array}{l}\text { Inadequate }=85.71 \% \\
\text { Foods not listed on TACO }=14.28 \%\end{array}$ & 0.00 \\
\hline App6 & $\begin{array}{l}\text { Inadequate }=85.71 \% \\
\text { Foods not listed on TACO }=14.28 \%\end{array}$ & 21.43 \\
\hline App7 & $\begin{array}{l}\text { Inadequate }=71.43 \% \\
\text { Foods not listed on TACO }=14.28 \% \\
\text { Flaw in the app }=14.28 \%\end{array}$ & $50 \cdot 00$ \\
\hline App8 & Does not have database with list of foods & \\
\hline App9 & $\begin{array}{l}\text { Inadequate }=85 \cdot 71 \% \\
\text { Foods not listed on TACO }=14 \cdot 28 \%\end{array}$ & $50 \cdot 00$ \\
\hline App10 & $\begin{array}{l}\text { Inadequate }=85 \cdot 71 \% \\
\text { Foods not listed on TACO }=14 \cdot 28 \%\end{array}$ & 21.43 \\
\hline App11 & $\begin{array}{l}\text { Inadequate }=85.71 \% \\
\text { Foods not listed on TACO }=14.28 \%\end{array}$ & 42.85 \\
\hline App12 & $\begin{array}{l}\text { Inadequate }=85.71 \% \\
\text { Foods not listed on TACO }=14.28 \%\end{array}$ & 35.71 \\
\hline App13 & $\begin{array}{l}\text { Partially adequate }=42 \cdot 86 \% \\
\text { Inadequate }=42.86 \% \\
\text { Foods not listed on TACO }=14.28 \%\end{array}$ & 28.57 \\
\hline $\begin{array}{l}\text { App14 } \\
\text { App15 }\end{array}$ & $\begin{array}{l}\text { Partially adequate }=85.71 \% \\
\text { Foods not listed on TACO }=14.28 \% \\
\text { Does not have database with list of foods }\end{array}$ & $50 \cdot 00$ \\
\hline App16 & $\begin{array}{l}\text { Inadequate }=85.71 \% \\
\text { Foods not listed on TACO }=14.28 \%\end{array}$ & 35.71 \\
\hline
\end{tabular}

TACO, Brazilian Food Composition Table, $2011^{(8)}$

'Foods not listed on TACO' refer to whole milk and cooked pasta. 'Flaw in the app' means the app did not follow the command to access information of these foods. *The foods selected for analysis (refined sugar, cooked white rice, Lady Finger banana, boiled potatoes, grilled steak (sirloin steak), cooked carioca beans, whole milk, unsalted butter, canola oil, French rolls, tomatoes) made up the basic Brazilian food basket for the month of August 2015. Other foods commonly consumed by the Brazilian population (loose leaf lettuce, cooked pasta, colabased soda) were also included. foods without description of all macro- and micronutrients present in TACO but, when they were described, the values were correct. Eleven apps presented from 28.57 to $85.71 \%$ of foods without description of macro- and micronutrients existing in TACO and, when described, the values were incorrect. Furthermore, two apps did not describe any macro- or micronutrient. Foods evaluated as 'not listed on TACO' refer to whole milk and cooked pasta.

The reliability of information on food energy value varied greatly between the apps. The app with higher percentage of correct information was App3 (57.14\%), while App5 did not report any energy value correctly (Table 2).

\section{Discussion}

The evaluated apps presented as main goals: monitoring the diet and physical exercise practised by users; following daily meals; controlling energy ingested; promoting healthy habits; and adopting a healthy lifestyle. This finding agrees with the study of Pagoto et al. ${ }^{(13)}$, which had as its main goal determining the degree to which weight-loss mobile apps included evidence-based behavioural strategies and found that most mobile apps included as goals weight loss, energy balance and establishment of diet. In the same way as nutrition-related apps propose behavioural change, there are apps for the practice of physical activity with the same goal. A study ${ }^{(14)}$ investigating fifty-seven apps involving behaviour change techniques regarding physical activity showed that the main ones used were: offering feedback on user performance; proposing that users monitor their behaviour; setting goals; planning support from other individuals; and showing instructions on how to change behaviour.

The calculation of BMI was absent in $56 \%$ of the apps we evaluated. Although widely used in nutritional practice owing to it being a simple calculation, BMI is unreliable in some cases, such as that of athletes, since they often present a low level of body fat and a high level of lean mass, with a BMI above the desirable ${ }^{(15)}$. Therefore, although the use of apps is an advantage, if there is no monitoring by trained health-care professionals, the apps can be used and interpreted wrongly.

Few apps in the present study mentioned their source of information about food composition and energy values, which hinders a more rigorous evaluation, since reliable sources may differ in the information they provide about food composition and energy. Dunford et al. ${ }^{(16)}$ created an app called FoodSwitch, which allows access to quick and easy information on the nutritional characteristics of foods. This app was first released in Australia and is currently available in New Zealand and the UK. According to the authors, each location requires its own database, because barcodes and nutrition information of foods vary from place to place, even though these foods are equal. Thus, 
the inadequacies and differences in food nutritional composition and energy content assessed based on the selected reference tables may be arising from the apps' use of sources of information different from the ones we chose, which reinforces the need to make this type of information available to the user (lay or professional).

Nevertheless, one cannot rule out the possibility of the information being incorrect. In their study with sports nutritionists (referred to by the authors as 'users') who had used diet-related apps in clinical practice, Jospe et al. ${ }^{(17)}$ noted that $95 \%$ of users reported limitations when using these apps. They mentioned problems in the nutrient database of foods, in addition to the incorrect choice of portion size by the patient and the selection of foods being considered inadequate.

We observed that most (81.25\%) apps received number of stars greater than or equal to 4 . However, $40-50 \%$ or more of the information about energy value was incorrect. The same applies to the foods' nutritional composition, as already mentioned. That is, the apps were well evaluated by users and therefore were used by them, but they provided unreliable information.

Some positive characteristics were identified by users: daily food $\log$ and subsequent quantification of energy intake; water intake record; possibility of updating anthropometric measurements and weight; graphs to follow the evolution of weight; motivational phrases; notifications about meal time, water intake and physical activity; indication of energy balance (amount of calories ingested in the day and amount that should be eaten until the end of the day); interaction with social networks; suggestion of healthy recipes; option to add some food that was not included in the database of the app; food diary; and record of the practice of physical activity. However, some negative aspects were also mentioned: users are able to customize their nutritional goals; absence of a list of macro- and micronutrients in some apps; some functions of the apps could only be accessed if the user subscribed to the suggested package; and difficulties of app update and use. In addition, Brazilian users said that international apps presented different information about food composition and referred to measures not used in Brazil, indicating the need for cultural adaptation of apps developed in other countries.

Other studies ${ }^{(18-22)}$ showed similar positive characteristics and others that we can add: app structure and possibility of use on a smartphone; use in real time; feedback that the app offered motivated the increased practice of physical activity; ease of use; graphical evolution of weight; help in understanding negative eating habits and changes in what one thought about foods; and to follow a diet, the use of the app is more convenient and easier than other methods.

The quantification of energy, present in most apps, is advantageous because it controls the user's energy intake; on the other hand, if the user does not have any monitoring by health-care professionals, the effect can be opposite, with the user observing only the number of calories in the food and not their quality, which may lead to a severe eating disorder in the future. Another fact that may lead to the development of eating disorders is the possibility for users to customize their nutritional goal. This option is not adequate because, without monitoring from a nutritionist, the user may underestimate or overestimate their energy and nutrient needs. Indeed, a study conducted among 105 participants diagnosed with an eating disorder showed that use of a specific nutritional app, which had the function of counting calories, contributed to the eating disorder, according the report of the study participants ${ }^{(23)}$.

In general, the food database of the nutrition apps helps the user to know the nutritional information of the food and also offers the possibility to add common foods consumed $^{(24)}$. The option of adding a new food to the database of the app may or may not have beneficial effect. The positive point found is the possibility of increasing the app's database; on the other hand, if the user does not know how to use this tool or does not use a reliable source, the data will be incorrect. To provide accuracy for the data it is important to use the yield and retention factors at the moment of the elaboration of the food composition database and labels, since those factors help to estimate the nutrient content of prepared foods ${ }^{(25)}$.

Therefore, the current study has verified that the apps on nutrition available today in Brazil need to be standardized in their sources of information and some of them need to simplify their usage. Thus, it is necessary to develop more comprehensive apps and with different characteristics, but reliable to be useful for nutritional guidance.

According to a study done in $2014^{(26)}$ that included a literature review and analysis of apps related to nutrition, dietetics and healthy habits, apps aim to contribute positively to users' health, besides helping to prevent diseases. However, some apps are flawed and proper understanding of the operation of this tool is needed for its best use.

\section{Conclusions}

The mobile apps for nutrition currently available in Brazil and evaluated in the current study are not useful for nutritional guidance because most of them are not based on reliable sources of information.

On the other hand, we consider that trustworthy apps could be used if the user is oriented by health-care professionals trained for this purpose. Beyond that, more trials are necessary, including more apps and user populations, and more analyses of use, to know what apps could be good for health care and to help lifestyle change.

\section{Acknowledgements}

Financial support: The authors thank Espaço da Escrita, Coordenadoria Geral da Universidade, University of 
Campinas (UNICAMP) for the language services provided. This work was supported by the National Council for Scientific and Technological Development (CNPq) (grant number 304610/2013-5). CNPq had no role in the design, analysis or writing of this article. Conflict of interest: None. Authorship: The authors declare that both participated sufficiently in the work to take public responsibility for the content of the paper. Both made substantive contributions to the conception and design of the study; the generation, collection, assembly, analysis and interpretation of data; the drafting or revision of the manuscript; and approval of the final version of the manuscript. Ethics of human subject participation: This study did not involve human subjects because nutritional apps were analysed; however, the authors followed ethical guidelines and the names of these apps were preserved.

\section{References}

1. Curioni CC, Brito FSB \& Boccolini CS (2013) O uso de tecnologias de informação e comunicação na área da nutrição. J Bras Telessaude 2, 105-111.

2. Caivano S, Ferreira BJ \& Domene SMA (2014) Avaliação da usabilidade do Guia Alimentar Digital móvel segundo a percepção dos usuários. Cienc Saude Colet 19, 1437-1446.

3. Coughein SS, Whitehead M, Sheats JQ et al. (2015) Smartphone applications for promoting healthy diet and nutrition: a literature review. Jacobs J Food Nutr 2, 021.

4. Boyce B (2014) Nutrition apps: opportunities to guide patients and grow your career. J Acad Nutr Diet 114, 13-15.

5. Lieffers JRL, Vance VA \& Hanning RM (2014) Use of mobile device applications in Canadian dietetic practice. Can J Diet Pract Res 75, 41-47.

6. Holzmann SL, Proll K, Hauner H et al. (2017) Nutrition apps quality and limitations. An explorative investigation on the basis of selected apps. Ernabrungs Umschau 64, 80-89.

7. Granado-Font E, Flores-Mateo G, Sorlí-Aguilar $\mathrm{M}$ et al. (2015) Effectiveness of a smartphone application and wearable device for weight loss in overweight or obese primary care patients: protocol for a randomised controlled trial. BMC Public Health 15, 531.

8. Núcleo de Estudos e Pesquisas em Alimentação (2011) Tabela Brasileira de Composição de Alimentos - TACO, 4th ed. http://www.nepa.unicamp.br/taco/contar/taco_4_edicao_ ampliada_e_revisada.pdf?arquivo=taco_4_versao_ampliada_ e_revisada.pdf (accessed September 2015).

9. Philippi ST (2002) Tabela de Composição de Alimentos: Suporte para Decisão Nutricional, 2nd ed. Brasilia: Editora Coronário.

10. Instituto Brasileiro de Geografia e Estatística (1999) Estudo Nacional da Despesa Familiar: Tabela de Composição de Alimentos, 5th ed. Rio de Janeiro: IBGE.

11. World Health Organization (1995) Physical Status: The Use and Interpretation of Antbropometry. Report of a WHO Expert Committee. WHO Technical Report Series no. 854. Geneva: WHO.

12. Departamento Intersindical de Estatística e Estudos Socioeconômicos (2015) Valor da cesta básica diminui em 15 cidades. http://www.dieese.org.br/analisecestabasica/2015/ 201508cestabasica.pdf (accessed September 2015).
13. Pagoto S, Schneider K, Jojic M et al. (2013) Evidence-based strategies in weight-loss mobile apps. Am J Prev Med $\mathbf{4 5}$, $576-582$.

14. Middelweerd A, Mollee JS, van der Wal CN et al. (2014) Apps to promote physical activity among adults: a review and content analysis. Int J Behav Nutr Phys Act 11, 97.

15. Gonçalves R, Mascarenhas LPG, Liebl EC et al. (2014) Grau de concordância do IMC e do IAC com percentual de gordura corporal. Rev Bras Qual Vida 6, 8-16.

16. Dunford E, Trevena H, Goodsell C et al. (2014) FoodSwitch: a mobile phone app to enable consumers to make healthier food choices and crowdsourcing of national food composition data. JMIR Mhealth Uhealth 2, e37.

17. Jospe MR, Fairbairn KA, Green P et al. (2015) Diet app use by sports dietitians: a survey in five countries. JMIR Mhealth and Whealth $\mathbf{3}$, e7.

18. Allen JK, Stephens J, Dennison Himmelfarb CR et al. (2013) Randomized controlled pilot study testing use of smartphone technology for obesity treatment. J Obes 2013, 151597.

19. Bond DS, Thomas JG, Raynor HA et al. (2014) B-MOBILE a smartphone-based intervention to reduce sedentary time in overweight/obese individuals: a within-subjects experimental trial. PLoS One 9, e100821.

20. Brindal E, Hendrie G, Freyne J et al. (2013) Design and pilot results of a mobile phone weight-loss application for women starting a meal replacement programme. J Telemed Telecare 19, 166-174.

21. Burns MN, Begale M, Duffecy J et al. (2011) Harnessing context sensing to develop a mobile intervention for depression. J Med Internet Res 13, e55.

22. Carter MC, Burley VJ, Nykjaer C et al. (2013) Adherence to a smartphone application for weight loss compared to website and paper diary: pilot randomized controlled trial. J Med Internet Res 15, e32.

23. Levinson CA, Fewell L \& Brosof LC (2017) My Fitness Pal calorie tracker usage in the eating disorders. Eat Disord 27, $14-16$.

24. Schumer H, Amadi C \& Joshi A (2018) Evaluating the dietary and nutritional apps in the Google Play Store. Health Inform Res 24, 38-45.

25. European Food Information Resource (2014) Report on collection of rules on use of recipe calculation procedures including the use of yield and retention factors for imputing nutrient values for composite foods. EuroFIR Technical Reports. http://www.eurofir.org/report-on-collection-of-ruleson-use-of-recipe-calculation-procedures-including-the-use-ofyield-and-retention-factors-for-imputing-nutrient-values-forcomposite-foods/\# (accessed March 2018).

26. Martín ISM, Fernández MG \& Yurrita LC (2014) Aplicaciones móviles en nutrición, dietética y hábitos saludables: análisis y consecuencia de una tendencia a la alza. Nutr Hosp 30, $15-24$.

27. Guedes DP \& Guedes JERP (1994) Composição Corporal: Princípios, Técnicas e Aplicações, 2nd ed. Londrina: Editora APEF.

28. Harris JA \& Benedict FG (1919) Biometric Studies of Basal Metabolism in Man. Washington, DC: Carnegie Institute of Washington.

29. Ainsworth BE, Haskel WL, Leon AS et al. (1993) Compendium of physical activities: energy costs of human movement. Med Sci Sports Exerc 25, 71-80.

30. Brasil Ministério da Saúde (2014) Guia alimentar para a população brasileira. http://pesquisa.bvsalud.org/bvsms/ resource/pt/mis-36719 (accessed April 2018). 